\title{
FIXED POINTS AND GENERALIZED HYERS-ULAM STABILITY OF QUADRATIC FUNCTIONAL EQUATIONS
}

\author{
CHOONKIL PARK AND THEMISTOCLES M. RASSIAS
}

Abstract. Let $X, Y$ be complex vector spaces. It is shown that if a mapping $f: X \rightarrow Y$ satisfies

$$
f(x+i y)+f(x-i y)=2 f(x)-2 f(y)
$$

or

$$
f(x+i y)-f(i x+y)=2 f(x)-2 f(y)
$$

for all $x, y \in X$, then the mapping $f: X \rightarrow Y$ satisfies

$$
f(x+y)+f(x-y)=2 f(x)+2 f(y)
$$

for all $x, y \in X$.

Furthermore, we prove the generalized Hyers-Ulam stability of the functional equations $(0.1)$ and $(0.2)$ in complex Banach spaces.

Mathematics subject classification (2000): 39B72, 47H10.

Key words and phrases: Quadratic mapping, fixed point, quadratic functional equation, generalized Hyers-Ulam stability.

\section{REFERENCES}

[1] C. BAAK, D. BOO AND TH. M. Rassias, Generalized additive mapping in Banach modules and isomorphisms between $C^{*}$-algebras, J. Math. Anal. Appl. 314 (2006), 150-161.

[2] B. Belaid, E. Elhoucien AND Th. M. Rassias, On the generalized Hyer-Ulam stability of the quadratic functional equation with a general involution, Nonlinear Functional Analysis (to appear).

[3] L. CĂDARIU AND V. RADU, Fixed points and the stability of Jensen's functional equation, J. Inequal. Pure Appl. Math. 4, no. 1, Art. ID 4 (2003).

[4] L. CĂDARIU AND V. RADU, On the stability of the Cauchy functional equation: a fixed point approach, Grazer Math. Ber. 346 (2004), 43-52.

[5] P. W. CholewA, Remarks on the stability of functional equations, Aequationes Math. 27 (1984), $76-86$.

[6] S. CZERWIK, On the stability of the quadratic mapping in normed spaces, Abh. Math. Sem. Univ. Hamburg 62 (1992), 59-64.

[7] J. DiAZ AND B. MARGOLIS, A fixed point theorem of the alternative for contractions on a generalized complete metric space, Bull. Amer. Math. Soc. 74 (1968), 305-309.

[8] P. GĂVRUTA, A generalization of the Hyers-Ulam-Rassias stability of approximately additive mappings, J. Math. Anal. Appl. 184 (1994), 431-436.

[9] D. H. HYERS, On the stability of the linear functional equation, Proc. Nat. Acad. Sci. U.S.A. 27 (1941), 222-224.

[10] D. H. Hyers, G. IsAC AND Th.M. Rassias, Topics in Nonlinear Analysis and Applications, World Scientific Publishing Co., Singapore, New Jersey, London, 1997.

[11] D. H. Hyers, G. IsAC AND TH.M. RASSIAS, Stability of Functional Equations in Several Variables, Birkhäuser, Basel, 1998. 
[12] F. H. Hyers AND Th. M. Rassias, Approximate homomorphisms, Aequationes Math. 44 (1992), $125-153$.

[13] G. IsAC AND TH. M. RASSIAS, Stability of $\psi$-additive mappings: Appications to nonlinear analysis, Internat. J. Math. Math. Sci. 19 (1996), 219-228.

[14] K. JUN AND H. KIM, On the stability of an $n$-dimensional quadratic and additive functional equation, Math. Inequal. Appl. 9 (2006), 153-165.

[15] S. Jung, Hyers-Ulam-Rassias Stability of Functional Equations in Mathematical Analysis, Hadronic Press, Palm Harbor, Florida, 2001.

[16] D. KANG AND H. CHU, On the Hyers-Ulam-Rassias stability of an $n$-dimensional quadratic functional equation, Math. Inequal. Appl. 10 (2007), 111-124.

[17] G. KIM, A generalization of Hyers-Ulam-Rassias stability of the $G$-functional equation, Math. Inequal. Appl. 10 (2007), 351-358.

[18] C. PARK, On the stability of the linear mapping in Banach modules, J. Math. Anal. Appl. 275 (2002), $711-720$

[19] C. PARK, On an approximate automorphism on a $C^{*}$ - algebra, Proc. Amer. Math. Soc. 132 (2004), 1739-1745.

[20] C. PARK, Lie *-homomorphisms between Lie $C^{*}$-algebras and Lie $*$-derivations on Lie $C^{*}$ - algebras, J. Math. Anal. Appl. 293 (2004), 419-434.

[21] C. PARK, Homomorphisms between Lie JC -algebras and Cauchy-Rassias stability of Lie $J C^{*}$ - algebra derivations, J. Lie Theory 15 (2005), 393-414.

[22] C. PARK, Homomorphisms between Poisson JC* - algebras, Bull. Braz. Math. Soc. 36 (2005), 79-97.

[23] C. PARK, Hyers-Ulam-Rassias stability of a generalized Euler-Lagrange type additive mapping and isomorphisms between $C^{*}$-algebras, Bull. Belgian Math. Soc.-Simon Stevin 13 (2006), 619-631.

[24] C. PARK, Fixed points and Hyers-Ulam-Rassias stability of Cauchy-Jensen functional equations in Banach algebras, Fixed Point Theory and Applications 2007, Art. ID 50175 (2007).

[25] C. PARK, Hyers-Ulam-Rassias stability of a generalized Apollonius-Jensen type additive mapping and isomorphisms between $C^{*}-$ algebras, Math. Nachr. (to appear).

[26] C. PARK AND J. CUI, Generalized stability of $C^{*}$-ternary quadratic mappings, Abstract Appl. Anal. 2007, Art. ID 23282 (2007).

[27] C. PARK AND J. HOU, Homomorphisms between $C^{*}$-algebras associated with the Trif functional equation and linear derivations on $C^{*}$-algebras, J. Korean Math. Soc. 41 (2004), 461-477.

[28] C. PARK AND A. NAJATI, Homomorphisms and derivations in $C^{*}$-algebras, Abstract Appl. Anal. 2007, Art. ID 80630 (2007).

[29] C. PARK AND J. PARK, Generalized Hyers-Ulam stability of an Euler-Lagrange type additive mapping, J. Difference Equ. Appl. 12 (2006), 1277-1288.

[30] C. PARK AND TH. M. RASSIAS, On a generalized Trif's mapping in Banach modules over a $C^{*}$-algebra, J. Korean Math. Soc. 43 (2006), 323-356.

[31] V. RADU, The fixed point alternative and the stability of functional equations, Fixed Point Theory 4 (2003), 91-96.

[32] TH. M. Rassias, On the stability of the linear mapping in Banach spaces, Proc. Amer. Math. Soc. 72 (1978), 297-300.

[33] TH. M. Rassias, On modified Hyers-Ulam sequence, J. Math. Anal. Appl. 158 (1991), 106-113.

[34] TH. M. RASSIAS, On the stability of the quadratic functional equation and its applications, Studia Univ. Babes-Bolyai XLIII (1998), 89-124.

[35] TH. M. RASSIAS, The problem of S.M. Ulam for approximately multiplicative mappings, J. Math. Anal. Appl. 246 (2000), 352-378.

[36] TH. M. RASSIAS, On the stability of functional equations in Banach spaces, J. Math. Anal. Appl. 251 (2000), 264-284.

[37] TH. M. RASSIAS, On the stability of functional equations and a problem of Ulam, Acta Appl. Math. 62 (2000), 23-130.

[38] TH. M. RASSIAS AND P. ŠEMRL, On the behavior of mappings which do not satisfy Hyers-Ulam stability, Proc. Amer. Math. Soc. 114 (1992), 989-993.

[39] TH. M. RASSIAS AND P. ŠEMRL, On the Hyers-Ulam stability of linear mappings, J. Math. Anal. Appl. 173 (1993), 325-338.

[40] TH.M. RASSIAS AND K. SHIBATA, Variational problem of some quadratic functionals in complex analysis, J. Math. Anal. Appl. 228 (1998), 234-253.

[41] F. SKOF, Proprietà locali e approssimazione di operatori, Rend. Sem. Mat. Fis. Milano 53 (1983), $113-129$.

[42] S. M. Ulam, Problems in Modern Mathematics, Wiley, New York, 1960. 
[43] D. ZHANG AND H. CAO, Stability of group and ring homomorphissms, Math. Inequal. Appl. 9 (2006), 521-528. 